\title{
Modal Analysis Of Automotive Rear Lamp Lens Produced From Plastic Material
}

\author{
Erhan Ay ${ }^{1}$, Barış Ediz ${ }^{1}$, Taner Çal ${ }^{1}$ and Sevda Telli Çetin ${ }^{2}$ \\ 0000-0001-9621-6030, 0000-0002-2704-7090, 0000-0003-3651-7872, 0000-0002-3281-9112
}

${ }^{1} R \& D$ Department/Magneti Marelli Mako Elektrik Sanayi ve Ticaret A.Ş., Turkey
${ }^{2}$ Mechanical Engineering Department/Uludağ University, Turkey

\section{Abstract}

In this study; first of all, finite element undamped modal analysis was performed on one of the automotive rear lamp lenses and were obtained natural frequencies and mode shapes. Then, Frequency Response Functions (FRF) of an automotive rear lamp lens, made of polymethyl methacrylate (PMMA) material, were obtained by using Impact Hammer Test Methods. Two different test methods can be used in the modal test by using impact hammer and accelerometer.

One of them,

- To move the hammer on the measuring points

Another is to move the accelerometer on the measuring points.

In both test methods, dynamic characteristics of the structure, natural frequencies, damping ratios and mode shapes were obtained. Damping ratios were calculated from the FRF's by using the Half Power Method. Finite Element Analysis (FEA) results and test results were compared and the best test method was determined.

The results obtained from both test methods were compared with the finite element undamped modal analysis results and the results are below.

- For FEA results and roving hammer test results error rates respectively; $14,597 \%$ and $16,781 \%$,

- For FEA results and roving accelerometer test results error rates respectively; $9,006 \%$ and $9,643 \%$.

Keywords: Automotive Rear Lamp, Finite Element Analysis, Frequency Response Function (FRF), Half Power Method, Impact Hammer Test Method, Modal Analysis

\author{
* Corresponding author \\ Erhan Ay \\ erhan.ay@magnetimarelli.com
}

Adress: Magneti Marelli Mako Elektrik Sanayi ve Ticaret A.Ş. Organize Sanayi Bölgesi Yeşil Cad. No:28 16159, Bursa, Turkey

Tel:+902242195995

Researh Article

Manuscript

Received 17.06.2019

Revised 21.11.2019

Accepted 21.11.2019

Doi: 10.30939/ijastech..578812

\section{Introduction}

The automotive industry is in a constant dynamic development due to the changing market and competitive conditions at the global level. Until 2000, automobile stop lenses were made of glass material (rear lamp). By the developments in mold, injection and coating technologies, they are started to be obtained from PMMA which is thermoplastic material. In addition, the light permeability of this material is close to glass. Also, this material has high resistance to temperature, chemical, scratching and shocks. Most importantly, it is light and transparent when compared to the same size glass.

In 2007, a simple lighting system was composed of 35 pieces and then in 2017, it became a complex system with 417 parts. As the lighting systems are subjected to dynamic forces on the automobile, the vibration frequencies of these forces trigger the natural frequencies of the parts used and resonates the parts. Among the parts entering the resonance, dust is formed due to friction, and even in the case of resonance, parts are broken due to high amplitude displacements. In order to solve these and similar dynamic problems, it is necessary to determine the dynamic behavior of the structure. This means the determination of movements in the structure due to vibration in critical frequencies, which is called Experimental Modal Analysis (EMA) [1].

Schwarz ve Richardson (1999) in their study, they review all of the main topics associated with EMA (or modal testing), including making FRF measurements with a Fast Fourier Transform (FFT) analyzer, modal excitation techniques, and modal parameter estimation from a set of FRFs (curve fitting) [2].

Karuppaiah, Sujatha and Ramamurti (1999) in their study, vehicle has been discretized taking into account the chassis 


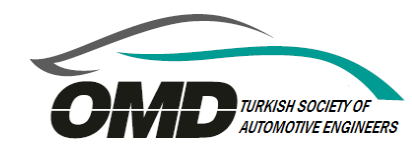

elements, axles, suspension and tires. The Lanczos method has been successfully used for the modal analysis. The power spectral density of acceleration of a track measured by using three height sensors has been fed as input to the tires and the dynamic response of the vehicle in terms of acceleration and strain has been computed at all the nodes using finite element modeling and the random vibration concept. The experiments were carried out using piezoelectric accelerometers and strain gauges to measure the vibration and strain levels at critical points of the vehicle. The vibration and strain levels calculated through FEA match well with the experimental values. Parametric study has also been carried out with a view to find the optimum suspension / tire characteristics for maximum ride comfort in the vehicle [3].

Storck, Sumali and Pu (2001) in their study, discusses EMA on an exhaust system of an off-road car. The exhaust structure is tested under three boundary conditions: free-free, supported with two elastomeric mounts, and mounted to the car. The free-free modal parameters are compared to finite element results. The two-mount tests are done with the mounts fixed to a rigid and heavy frame. The rigidity of the frame is verified experimentally. The on-car test is done with realistic boundary conditions, where the exhaust structure is fixed to the engine manifold as well as the two elastomeric mounts. The two-mount and the on-car tests result in highly complex mode shapes.

Details discussed in the paper include obtaining the measurement point coordinates, a method to attach triaxle accelerometers to align with coordinate axes, methods to ensure rigidity of the mounting frame, and the effects of non-proportional damping from the elastomeric mounts. Results from EMA provide data and validation to numerical models such as finite element models [4].

Schrader and Hilburger (2005) in their study, to show how a three axes random vibration simulation can be performed using FEA.

FEA is a very efficient way of proving designs and concepts without building expensive prototypes. A methodology for performing a three axes random vibration simulation using any given power spectral density function will be illustrated. As with all simulations, it is paramount to properly correlate the simulation to prove the methodology. Correlation method and data will be provided as part of proving the simulation methodology [5].

Şimşek (2010) in his study, the analysis of a vehicle cabin's vibration has been performed with the computer aid. After modelling the vehicle's cabin in the defined dimensions, using the "ANSYS Workbench" named computer program, its modal analysis has been performed and the cabin's natural frequencies were obtained. If the road roughness and other reason's excitation frequencies become equal or near to vehicle's natural frequency, the vibrations start to increase. For this reason, it is aimed that the cabin's natural frequency to be out of the frequency range of external reasons caused vibration. With this study the construction details, to get the

\section{required frequency, can be guessed [6].}

Pnadiyanayayam, Bardia and Putil (2011) in their study, focuses on the methodology to understand and predict the dynamic behavior of the system using various approaches (like theoretical, numerical and experimental). The modal response of the model is acquired through the theory of vibrations of continuous systems. The same model is analyzed by finite-element method and also by experiment, thus, determining its dynamic properties like modal frequencies, mode shapes etc. Thus, the results obtained through all these approaches are compared in detail. Further, with an effort to understand the force response behavior of the system, Random Vibration analysis is carried out using a commercially available standard finite element software on the same model using specified Power Spectral Density (PSD) level as an input excitation, results in, response PSD and transmissibility curve assuming different damping ratio. Same scenario is replicated with the random vibration testing and then, these various results are compared for deducing the appropriate damping ratio which is one of the very important factor for dynamic analysis. Furthermore, using the result of simulation corresponding to deduced damping ratio, fatigue life is predicted based on three band technique.

As, very small and delicate electronic components are mounted on both sides of the PCB using solder joints, adhesive etc, various nonlinearities are encountered while modelling them for analysis. For avoiding the model complexity and minimizing the affecting variable, a simple cantilever model is considered for the present study [7].

Thor and Chippa (2015) in their study, vibration analysis of existing design of outside rear view mirror is investigated through numerical model using FEA. Furthermore, these results are verified through experimental work. From the modal analysis, it was found that the natural frequency of outside rear view mirror is less than the excitation frequency (Engine \& Road excitation). However, to avoid resonance and for a safe design the natural frequency must be greater than these excitation frequencies. Therefore, the existing outside rear view model is modified by adding ribs at its base in order to increase the stiffness. It has been found that, with this design modification, the natural frequency of outside rear view mirror is increased, and is well ahead of the excitation frequency [8].

In this study, FRF's were obtained by applying the two methods of the Impact Hammer Test Method to the stop lens made of PMMA material and the damping ratios were calculated. The results obtained from the two test methods were compared with the results of the analysis and the best method will be determined.

The originality of this study is compared two modal testing methods performed on plastic components in which the damping properties are unknown. The second point of this study is to determined correct stress values by the use of correct damping ration during dynamic FEA analysis. Further- 
more as a result of having correct stress values fatigue analysis will be reliable.

\section{Material and Method}

\section{$2.1 \mathrm{EMA}$}

EMA is the process of determining the dynamic model of the structure by expressing the dynamic properties of a mechanical system or structure in terms of vibration parameters [9]. How to?

1. Preparation of the test structure (suitable support, application of the correct points as much as required)

\section{FRF measurement}

3. Parameter estimation (determination of natural frequencies, vibration modes and damping ratios with appropriate approaches in frequency or time domain)

\subsection{Impact hammer test}

Two different test methods can be used in the modal test which is taken from multiple points on the structure by using impact hammer and accelerometer.

One of them,

- $\quad$ in Figure 1, swing the hammer on the measuring points (Roving Hammer)

- $\quad$ in Figure 2, another is to move the accelerometer on the measuring points (Roving Accelerometer).

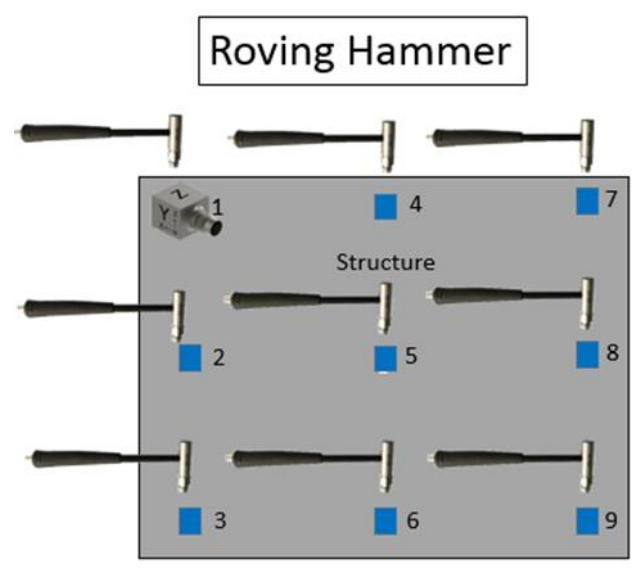

Fig. 1. Roving hammer test method

There are some advantages of the modal test done by moving the impact hammer, over the modal test done by moving the accelerometer. In the tests carried out by moving the accelerometer on the measuring points, it is necessary to remove and install the accelerometer at each measurement point. This method takes longer than the other test method.

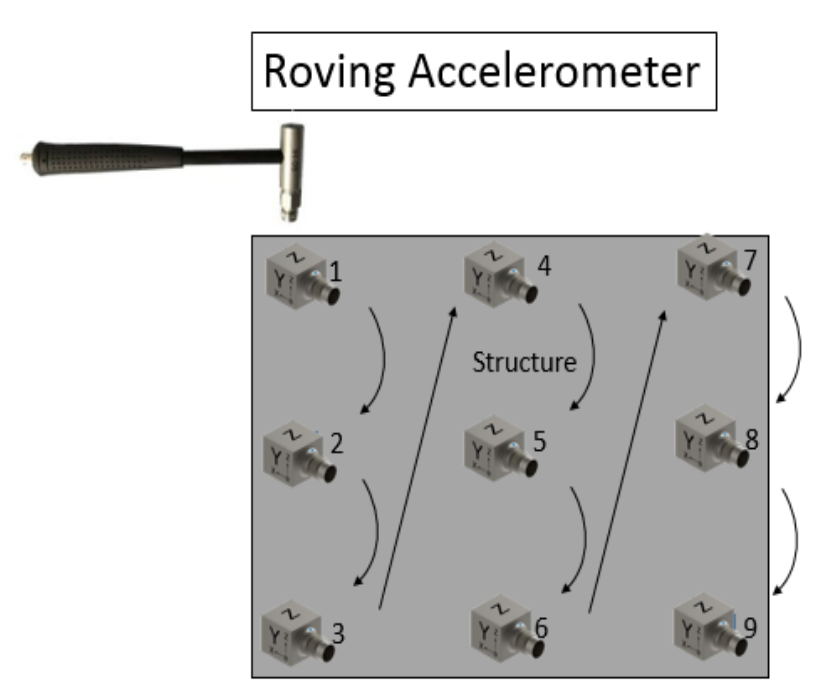

Fig. 2. Roving accelerometer test method

In addition, since the accelerometer is moved from one position to another position, the mass distribution of the structure will be constantly changing and the natural frequencies of the structure are affected [10].

In EMA, a known (measured) force is given to the structure and the response of the structure to this force is measured. In this process, a hammer is used to apply force to the structure, the accelerometer is used to measure the response of the structure and a signal analyzer is used to evaluate the data. The impact applied to the structure is measured in the time domain with a force transducer placed on the hammer head. Under this applied force, the structure makes a vibration movement depending on the boundary conditions and material properties. The response of the structure to this effect is measured with the accelerometer connected to the structure again in the time domain.

In Figure 3, by using FFT, the effect and response functions are converted from time domain to frequency domain. The FRF of the structure is obtained by dividing the Fourier transformed response function by the effect function at equation 1. FRF's are used to determine the natural frequencies, mode shapes and damping ratio of the structure [11].

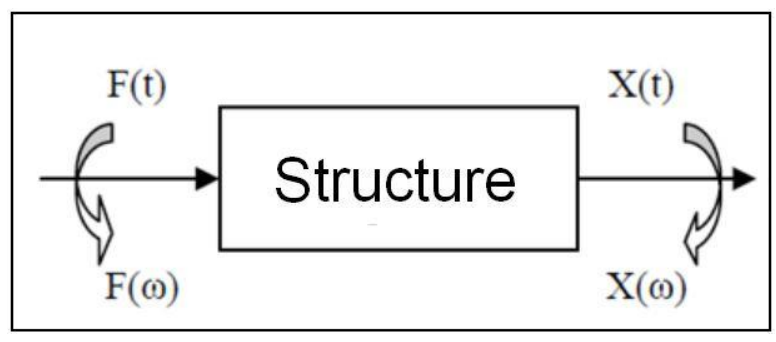

Fig. 3. FFT of effect and response functions 
$H(\omega)=\frac{X(\omega)}{F(\omega)}$

\subsection{Frequency Response Function Estimators}

In Figure 4 shows a traditional measurement-system model used to describe FRF measurement when noise is present on both measured force and response signals.

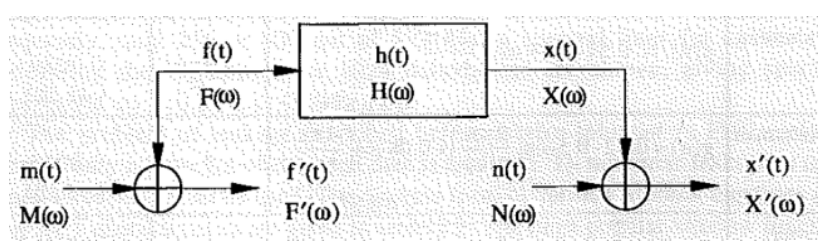

Fig. 4. A traditional measurement-system model

The conventional frequency response function estimator $\mathrm{H}_{1}(\omega)$ is determined by using the cross input-output spectrum and the input auto-spectrum:

$\mathbf{H}_{1}(\boldsymbol{\omega})=\frac{\mathbf{S}_{\mathbf{f}^{\prime} \mathbf{x}^{\prime}}(\boldsymbol{\omega})}{\mathbf{S}_{\mathbf{f}^{\prime} \mathbf{f}^{\prime}}(\boldsymbol{\omega})}$

Another version of the frequency response function estimator, $\mathrm{H}_{2}(\omega)$, is obtained by normalising the output auto-spectrum by the cross input-output spectrum:

$\mathbf{H}_{2}(\boldsymbol{\omega})=\frac{\mathbf{s}_{\mathbf{x}^{\prime} \mathbf{x}^{\prime}}(\boldsymbol{\omega})}{\mathbf{s}_{\mathbf{x}^{\prime} \mathbf{f}^{\prime}}(\boldsymbol{\omega})}$

As $H_{1}(\omega)$ and $H_{2}(\omega)$ should give the same result, an indicator of quality of the analysis can be defined as the ratio of these two estimators. Thus,

$$
\begin{aligned}
\frac{\mathbf{H}_{\mathbf{1}}(\boldsymbol{\omega})}{\mathbf{H}_{\mathbf{2}}(\boldsymbol{\omega})} & =\frac{\mathbf{S}_{\mathbf{f}^{\prime} \mathbf{x}^{\prime}}(\boldsymbol{\omega})}{\mathbf{S}_{\mathbf{f}^{\prime} \mathbf{f}^{\prime}}(\boldsymbol{\omega})} \frac{\mathbf{S}_{\mathbf{x}^{\prime} \mathbf{f}^{\prime}}(\boldsymbol{\omega})}{\mathbf{S}_{\mathbf{x}^{\prime} \mathbf{x}^{\prime}}(\boldsymbol{\omega})}=\frac{\mathbf{S}_{\mathbf{f}^{\prime} \mathbf{x}^{\prime}}(\boldsymbol{\omega}) \mathbf{S}_{\mathbf{f}^{\prime} \mathbf{x}^{\prime}}(\boldsymbol{\omega})}{\mathbf{S}_{\mathbf{f}^{\prime} \mathbf{f}^{\prime}}(\boldsymbol{\omega}) \mathbf{S}_{\mathbf{x}^{\prime} \mathbf{x}^{\prime}}(\boldsymbol{\omega})} \\
& =\frac{\left|\mathbf{S}_{\mathbf{f}^{\prime} \mathbf{x}^{\prime}}(\boldsymbol{\omega})\right|^{2}}{\mathbf{S}_{\mathbf{f}^{\prime} \mathbf{f}^{\prime}(\boldsymbol{\omega}) \mathbf{S}_{\mathbf{x}^{\prime} \mathbf{x}^{\prime}}(\boldsymbol{\omega})}}=\gamma^{2}(\boldsymbol{\omega})
\end{aligned}
$$

where $\boldsymbol{\gamma}^{2}(\omega)$ is called the ordinary coherence function [12].

The most commonly used estimator is the $\mathrm{H}_{1}$ estimator. It assumes that there is no noise on the input. All noise is assumed to be on the output.

Alternatively, the $\mathrm{H}_{2}$ estimator can be used. This assumes that there is no noise on the output. Noise is assumed to be only on input [13].

In this study, $\mathrm{H}_{2}$ estimator was used.

\subsection{Half Power Method}

In Figure 4, the Half Power Method is explained [14].
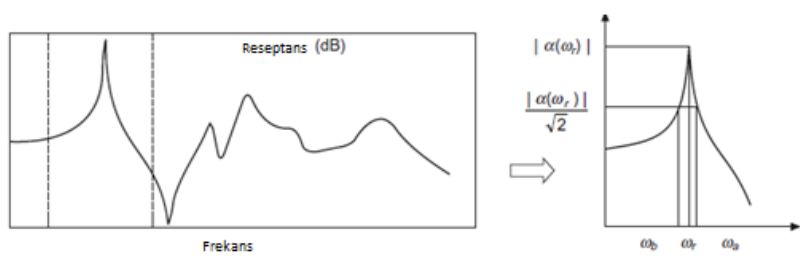

Fig. 4. Half Power Method

The equations used to calculate damping, damping ratios and modal constants in the half-power method are given in equation 2 and equation 3 [15].

$\eta_{\mathrm{r}}=\frac{\omega_{\mathrm{b}}^{2}-\omega_{\mathrm{a}}^{2}}{2 \omega_{\mathrm{r}}^{2}} \sim \frac{\omega_{\mathrm{b}}-\omega_{\mathrm{a}}}{\omega_{\mathrm{r}}}$

$\zeta_{\mathrm{r}}=\frac{\omega_{\mathrm{b}}^{2}-\omega_{\mathrm{a}}^{2}}{4 \omega_{\mathrm{r}}^{2}} \sim \frac{\omega_{\mathrm{b}}-\omega_{\mathrm{a}}}{2 \omega_{\mathrm{r}}}$

\subsection{FEA of an automotive rear lamp lens}

Finite Element modal analysis was performed to determine the natural frequencies and mode shapes of the test sample. For this purpose, the solid model of the sample was taken to the finite element program and the tetrahedron mesh was formed. Then, the modulus of elasticity and density were entered as the material properties and the undamping freefree modal analysis solution was made. Direct solver and Block Lanczos method were used. Natural frequencies and mode shapes were obtained as a result of analysis.

Table 1. Finite element computation

\begin{tabular}{l|l}
\hline & Mesh \\
\hline Type & Tetmesh \\
\hline Element Size & 4 \\
\hline Node Number & 86871 \\
\hline Element Number & 43668 \\
\hline
\end{tabular}

Table 2. Material properties

\begin{tabular}{l|l}
\hline Material & PMMA \\
\hline Density & $1190 \mathrm{~kg} / \mathrm{m}^{3}$ \\
\hline Young Modulus & $3360 \mathrm{MPa}$ \\
\hline Poisson Ratio & 0.32 \\
\hline
\end{tabular}




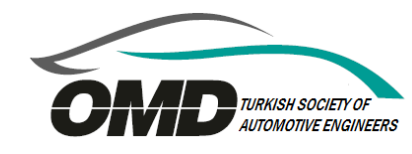

In Figure 5, first flexible body mode shape is illustrated.

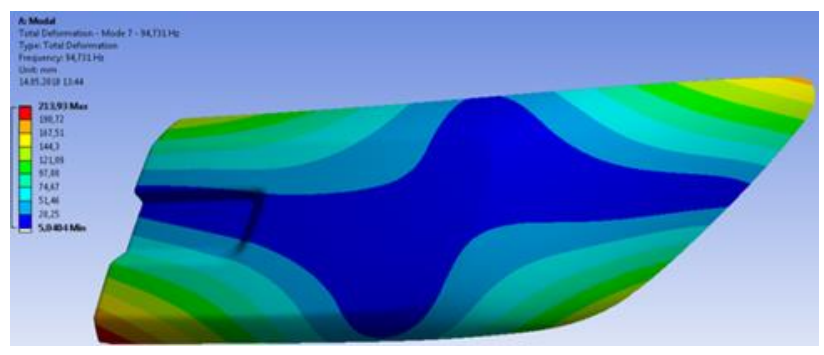

Fig. 5. 1. Mode shape $-94,731 \mathrm{~Hz}$

In Figure 6, second flexible body mode shape is illustrated.

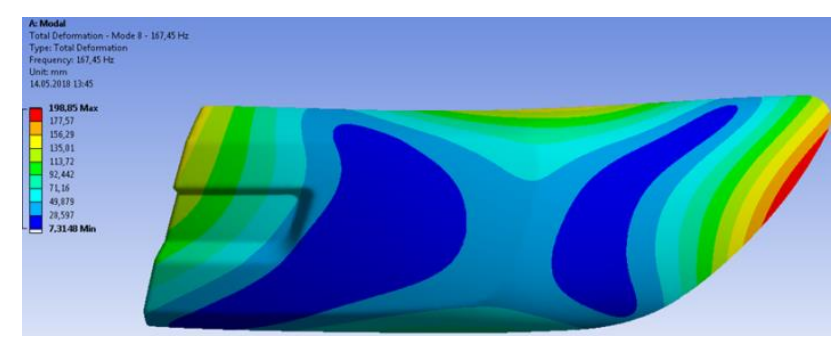

Fig. 6. 2. Mode shape $-167,45 \mathrm{~Hz}$

\subsection{Instrumentation}

In experimental modal analysis, a known force is given to the structure and the response of the structure to this force is measured. This process uses a hammer to apply force to the structure, an accelerometer to measure the response of the structure, and a data acquisition system to evaluate the data.

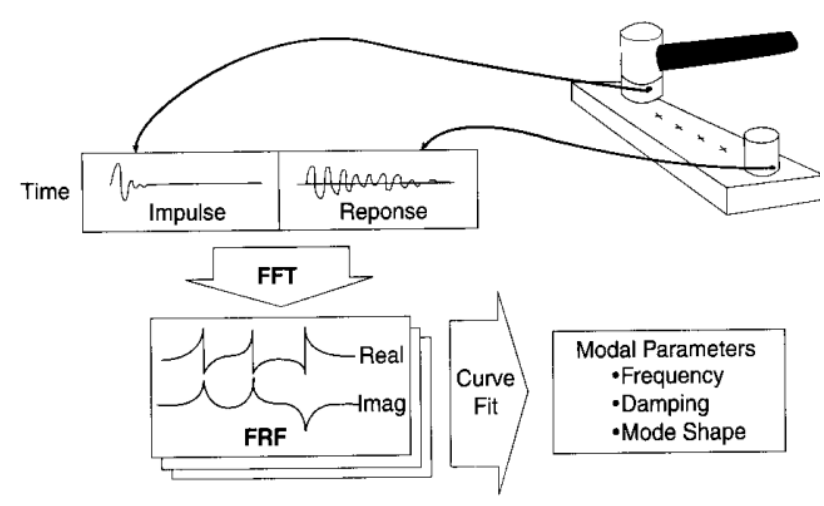

Fig. 7. Impact testing

Impact testing is depicted in Figure 7. The following equipments are required to perform an impact test,
1. An impact hammer with a force sensor attached to its head to measure the input force (Figure 8) [16].

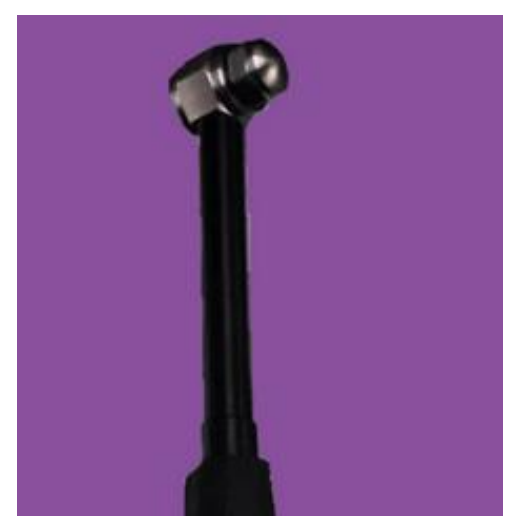

Fig. 8. Impact hammer

Table 3. Impact hammer properties

\begin{tabular}{l|l}
\hline Model & $\mathrm{IH}-01$ \\
\hline Sensitivity & $25 \mathrm{mV} / \mathrm{N}$ \\
\hline Hammer Head Weight & $28 \mathrm{gm}$ \\
\hline Hammer Head Diameter & $18 \mathrm{~mm}$ \\
\hline Hammer Length & $250 \mathrm{~mm}$ \\
\hline Output & BNC \\
\hline Tips Supplied & $\begin{array}{l}\text { Soft, medium, hard, alumini } \\
\text { um }\end{array}$ \\
\hline
\end{tabular}

The input force frequency range can be controlled by changing the hammer tip in two ways:

Hammer Mass - Decreasing the mass of the hammer tip causes the hammer to contact the structure for a shorter amount of time. The reduced mass allows the hammer to reverse directions more easily after hitting the structure, reducing the time it is in contact.

Hammer Stiffness - Increasing the stiffness of the tip allows shortens the duration that the hammer is in contact with the structure (Figure 9) [17].

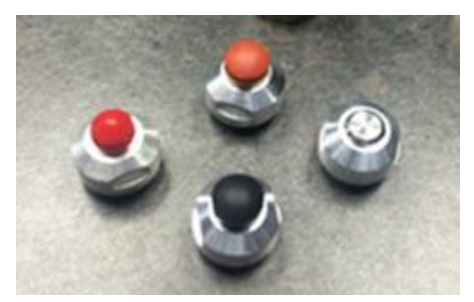

Fig. 9. Impact hammer tips 
2. An accelerometer to measure the response acceleration at a fixed point and direction (Figure 10) [18].

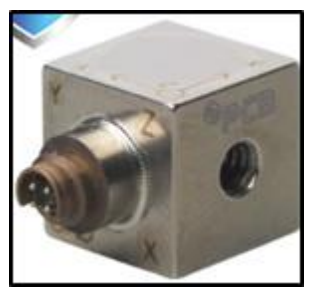

Fig. 10. Modal accelerometer with 3 axes

Table 4. Modal accelerometer properties

\begin{tabular}{l|l}
\hline Model & PCB 356B21 \\
\hline Sensitivity $( \pm 10 \%)$ & $10 \mathrm{mV} / \mathrm{g}$ \\
\hline Measurement Range & $\pm 500 \mathrm{~g} \mathrm{pk}$ \\
\hline Broadband Resolution & $0,004 \mathrm{grms}$ \\
\hline Frequency Range (X axis) & $2-7000 \mathrm{~Hz}$ \\
\hline $\begin{array}{l}\text { Frequency Range (Z or Y } \\
\text { axis) }\end{array}$ & $2-1000 \mathrm{~Hz}$ \\
\hline Weight & $4 \mathrm{gm}$ \\
\hline
\end{tabular}

3. Min. 2 channel data acquisition system to compute FRFs (Figure 11) [19].

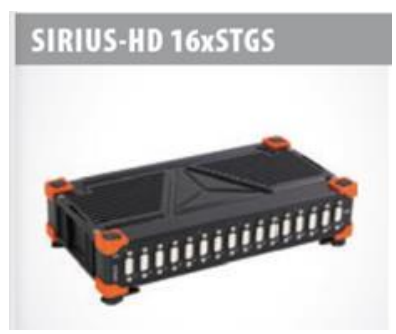

Fig. 11. Data acquisition system

Table 5. Data acquisition system properties

\begin{tabular}{|c|c|}
\hline Model & $\begin{array}{l}\text { DEWESoft Sirius HD } \\
\text { 16xSTGS }\end{array}$ \\
\hline Analog Input & $\begin{array}{l}16 \text { ch voltage, full/half/quarter } \\
\text { bridge strain, current }\end{array}$ \\
\hline ADC Type & $\begin{array}{l}24 \text { bit delta-sigma with anti- } \\
\text { alliasing filter }\end{array}$ \\
\hline Sampling Ratio & $200 \mathrm{kS} / \mathrm{sec}$ \\
\hline Dynamic Range @ 10kS & $137 \mathrm{~dB}$ \\
\hline Bridge Modes & $\begin{array}{l}\text { Full/half/quarter } \mathrm{Br} 120 / 350 \Omega \\
\text { 3-wire }\end{array}$ \\
\hline Excitation Voltage & 0 to $12 \mathrm{VDC}$ \\
\hline
\end{tabular}

\subsection{DEWESoft geometry editor}

In order to capture the mode shapes obtained from the Finite Element Model in the best way, the coordinates of the response and excitation points to be used in the modal tests are determined and marked on the lens surface.

These points are determined as follows;

1. Free-Free Modal analysis of the lens by the use of ANSYS software.

2. As a result of the analysis, mode shapes and the locations where the lens deflects most during resonances are determined.

3. Points are taken from the specified locations and the coordinates of these points according to the global axis are set.

4. In Figure 12, these coordinates were entered into DEWESoft's Geometry Editor Page and lens geometry was created.

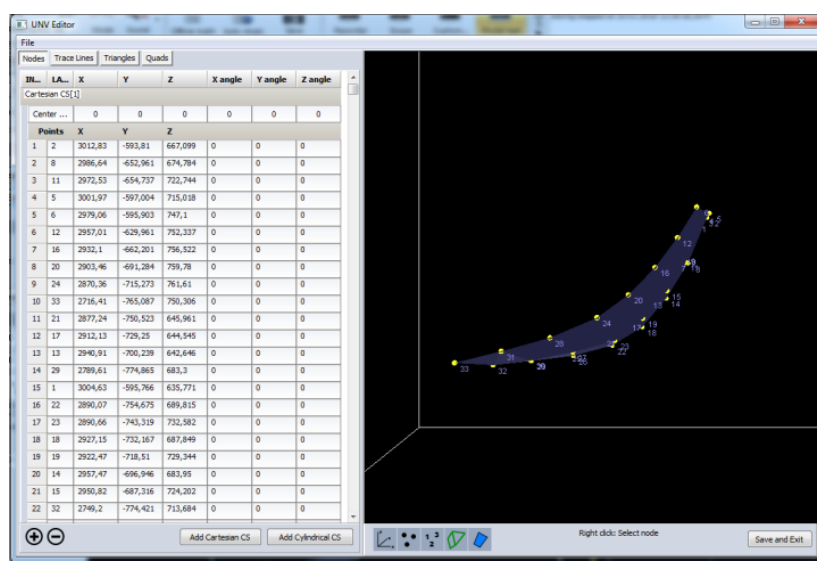

Fig. 12. DEWESoft geometry editor page

\subsection{Roving hammer impact test}

In Figure 13, the final product marked on the response and the excitation points is hung using a single elastic rope from the specified single point test apparatus to capture the condition closest to the free-free boundary conditions.

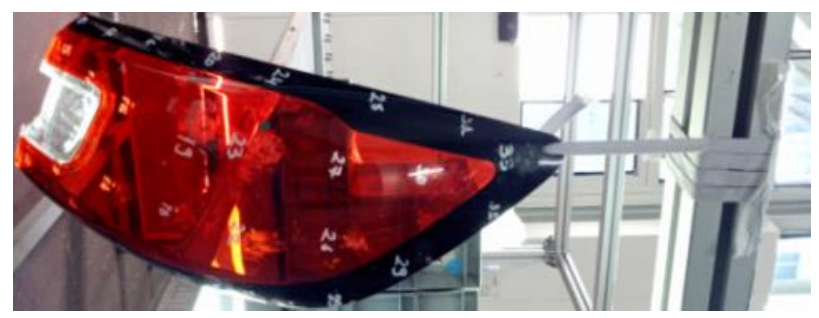

Fig. 13. Test sample 
FRF graphs were obtained from determined the points on the final product. Resonance points were determined by using FRF graphs and the damping ratio were calculated at these points. In Figure 14, shows all FRF curves of the roving hammer impact test method of the points on the sample.

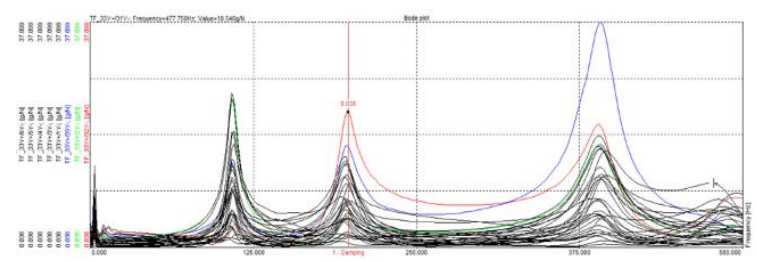

Fig. 14. All FRF results (Roving hammer impact test method)

In Figure 15, the first three modes of the roving hammer impact test method are illustrated.

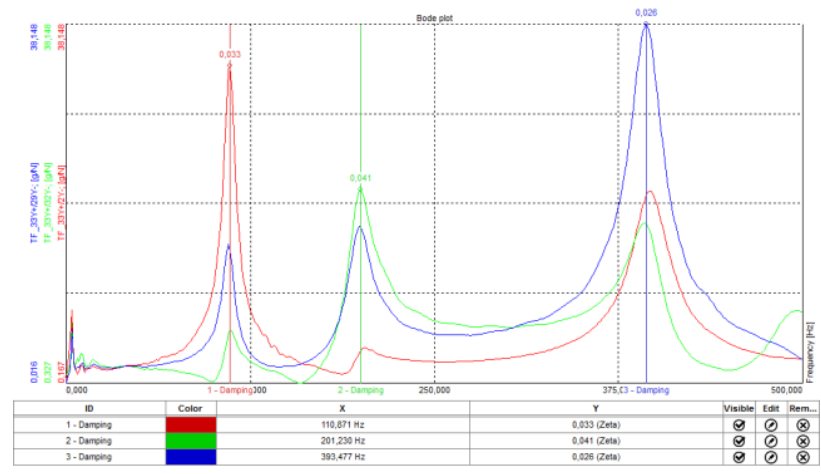

Fig. 15. Test sample FRF results (Roving hammer impact test method)

The damping ratios were calculated by using the half power method from the peaks in the Figure 15 and results are illustrated in Table 6.

Table 6. Roving hammer impact test results

\begin{tabular}{l|l|l|l}
\hline & $\begin{array}{l}\text { Frequency } \\
{[\mathrm{Hz}]}\end{array}$ & $\begin{array}{l}\text { Damping } \\
\text { Ratio }[\xi]\end{array}$ & $\begin{array}{l}\text { Amplitude } \\
{[\mathrm{g} / \mathrm{N}]}\end{array}$ \\
\hline 1.Mode & 110,871 & 0,033 & 33,720 \\
\hline 2.Mode & 201,230 & 0,041 & 20,728 \\
\hline
\end{tabular}

In Figure 16, shows all FRF curves of the roving accelerometer test method of the points on the sample.

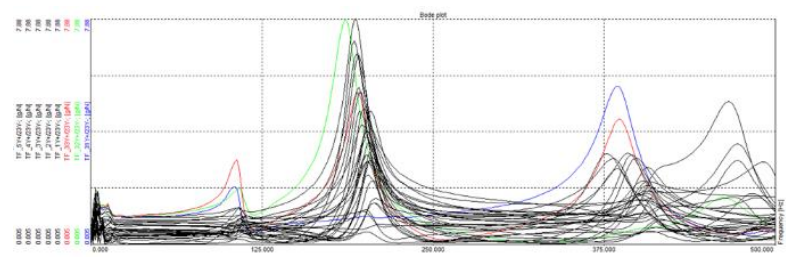

Fig. 16. Fig. 14. All FRF results (Roving accelerometer test method)
In Figure 17, the first three modes of the roving accelerometer impact test method are illustrated.

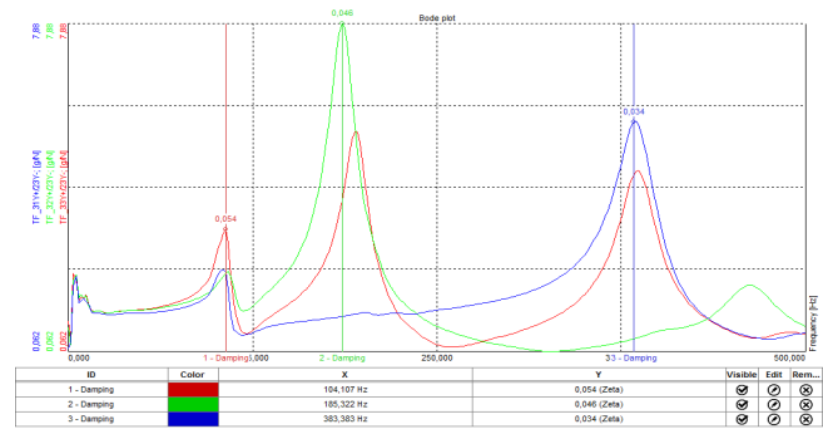

Fig. 17. Test sample FRF results (Roving accelerometer impact test method)

The damping ratios were calculated by using the half power method from the peaks in the Figure 17 and results are illustrated in Table 7.

Table 7. Roving accelerometer impact test results

\begin{tabular}{l|c|c|c}
\hline & $\begin{array}{c}\text { Frequency } \\
{[\mathrm{Hz}]}\end{array}$ & $\begin{array}{c}\text { Damping } \\
\text { Ratio }[\xi]\end{array}$ & $\begin{array}{c}\text { Amplitude } \\
{[\mathrm{g} / \mathrm{N}]}\end{array}$ \\
\hline 1.Mode & 104,107 & 0,054 & 2,985 \\
\hline 2.Mode & 185,322 & 0,046 & 7,880 \\
\hline
\end{tabular}

\section{Conclusions}

The test results were compared with the analysis results; the results of the test with the roving accelerometer were found to be closer than the results of the test with roving hammer. But the test with the roving accelerometer is more difficult than the test with roving hammer and it takes more time. In addition, the center of the gravity of the structure is constantly changing in the roving accelerometer test method, the natural frequencies of the structure are constantly affected.

Table 8. FEA results vs roving hammer test results compare

\begin{tabular}{c|c|c|c}
\hline & $\begin{array}{c}\text { Finite Element } \\
\text { Analysis }\end{array}$ & $\begin{array}{c}\text { Roving Hammer } \\
\text { Test }\end{array}$ & \\
\hline & Frequency $[\mathrm{Hz}]$ & Frequency $[\mathrm{Hz}]$ & $(\%)$ \\
\hline 1.Mode & 94,731 & 110,871 & 14,557 \\
\hline 2.Mode & 167,45 & 201,230 & 16,781 \\
\hline
\end{tabular}

Table 9. FEA results vs roving accelerometer test results com-

\begin{tabular}{c|c|c|c}
\hline & $\begin{array}{c}\text { Finite Element } \\
\text { Analysis }\end{array}$ & $\begin{array}{c}\text { Roving } \\
\text { Accelerometer Test }\end{array}$ & \\
\hline & Frequency $[\mathrm{Hz}]$ & Frequency $[\mathrm{Hz}]$ & $(\%)$ \\
\hline 1.Mode & 94,731 & 104,107 & 9,006 \\
\hline 2.Mode & 167,45 & 185,322 & 9,643 \\
\hline
\end{tabular}

Mode shapes of FEA results were compared with mode 
shapes of roving hammer test results and the results were confirmed. In Figure 18, shows the two mode shapes.

\section{Mode Shape}

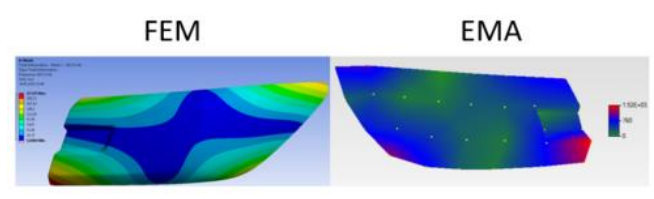

2. Mode Shape

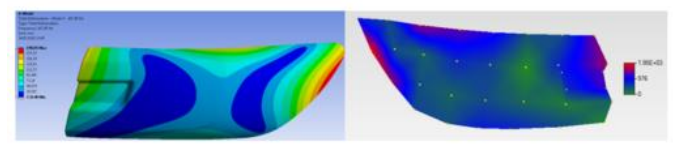

Fig. 18. Compared mode shapes between the FEM and roving hammer test method

The test results are affected by;

- $\quad$ Rigidity of the elastic rope used during the test,

- Hanging the final product to the test device,

- Depending on the weight of the accelerometer used.

As a result, roving hammer can be used in short term industrial studies and roving accelerometer test method in academic and R\&D studies.

\section{Nomenclature}

$\begin{array}{ll}\mathrm{X}(\omega) & : \text { Fourier transform of effect function }(\mathrm{g}) \\ \mathrm{F}(\omega) & : \text { Fourier transform of response function }(\mathrm{N}) \\ \mathrm{H}(\omega) & : \text { transfer function }(\mathrm{g} / \mathrm{N}) \\ \eta_{r} & : \text { damping loss factor of the r. mode } \\ S_{r} & : \text { damping ratio of the r. mode } \\ S_{f^{\prime} x^{\prime}}(\omega) & : \text { cross input-output spectrum } \\ S_{f^{\prime} f^{\prime}}(\omega) & : \text { input auto-spectrum } \\ S_{x^{\prime} x^{\prime}}(\omega) & : \text { output auto-spectrum } \\ S_{x^{\prime} f^{\prime}}(\omega) & : \text { cross input-output spectrum }\end{array}$

\section{References}

[1] Ay, E. (2019). Plastik Malzemeden Üretilmiş Otomotiv Aydınlatma Parçalarının Modal Analizi ve Sonlu Elemanlar Modelinin Güncellenmesi. MSc Thesis, BUÜ, Machine Theory and Dynamic, Bursa.

[2] Schwarz, B. J., Richardson, M. H. (1999). Experimental modal analysis. Vibrant Technology Inc., Jamestown, California, 12 pp.

[3] Karuppaiah, N., Sujatha, C., Ramamurti, V. (1999). Modal and vibration/stress analysis of passenger vehicle by FEM. SAE Technical Paper Series, doi: 10.4271/990003.

[4] Strock, H., Sumali, H., Pu, Y. (2001). Experimental modal analysis of automotive exhaust structures. SAE Technical Paper Series, doi: 10.4271/2001-01-0662.
[5] Schrader, C. D., Hilburger, F. K. N. (2005). Development and correlation of three axes random vibration simulation on automotive lighting. SAE Technical Paper Series, doi: 10.4271/2006-01-1570.

[6] Şimşek, A. (2010). Bir iş makinası kabininin modal analizi. Yüksek Lisans Tezi, SAÜ, Makine Mühendisliği Anabilim Dalı, Sakarya

[7] Pandiyanayagam, G., Barida, P., Patil, Y. (2011). Experimental and modeling studies towards random vibration. SAE Technical Paper Series, doi: 10.42712011-26-0118

[8] Thor, S., Chippa S. (2015). Dynamics analysis of outside rear view mirror. SAE Technical Paper Series, doi: 10.4271/201526-0220.

[9] Avitabile, P. (2001). Experimental Modal Analysis. Sound and Vibration

[10] Anonymous, Modal Tips: Roving Hammer versus Roving Accelerometer. https://community.plm.automation.siemens.com/t5/Testing-Knowledge-Base/Modal-Tips-RovingHammer-versus-Roving-Accelerometer/ta-p/378619

[11]Ewins, D.J. (1995). Modal Testing: Theory and Practice, John Wiley and Sons, Inc. New York.

[12] Maia, N., M., M. (1997). Theoretical and experimental modal analysis. British Library Cataloguing in Publication Data, 101-102.

[13] Anonymous, What is a frequency response function (FRF)?, https://community.sw.siemens.com/s/article/what-is-a-frequency-response-function-frf

[14] Anonymous, How to calculate damping from a FRF?. https://community.plm.automation.siemens.com/t5/Testing-

Knowledge-Base/How-to-calculate-damping-from-a-FRF/ta$\mathrm{p} / 355050$

[15] He, J., Fu, Z. F. (2001). Modal analysis, Butterworth-Heinemann, Oxford.

[16] Anonymous, DJB impact hammer IH-01, DJB Instruments, http://www.djbinstruments.com/products/instrumentation/impact-hammers/view/ih-01

[17] Anonymous, What modal impact hammer tip should i use?. https://community.plm.automation.siemens.com/t5/TestingKnowledge-Base/What-modal-impact-hammer-tip-should-Iuse/ta-p/355026

[18] Anonymous, PCB 356B21, PCB Piezotronics MTS Systems Corporation, http://www.pcb.com/products/model/356b21

[19] Anonymous, DEWESoft Sirius HD 16xSTGS, https://dewesoft.com/products/daq-systems/sirius 